\title{
Frenectomy as a Treatment Modality for Minimal Median Cleft of the Upper Lip
}

\author{
Revathy $\mathrm{V}^{* 1}$, Sarasakavitha ${ }^{2}$ and Jacob J ${ }^{2}$
}

${ }^{1}$ Department of Pedodontics and Preventive Dentistry, Karpaga Vinayaga Institute of Dental Sciences, Chennai, India

${ }^{2}$ Pediatric Dental Practitioner, Chennai, India

${ }^{*}$ Corresponding author: Revathy V, Department of Pedodontics and Preventive Dentistry, Karpaga Vinayaga Institute of Dental Sciences, Chennai, India, Tel: +00919025755447, E-mail: govisrev@rediffmail.com

Citation: Revathy V, Sarasakavitha, Jacob J (2016) Frenectomy as a Treatment Modality for Minimal Median Cleft of the Upper Lip. J Case Rep Stud 4(2): 203. doi: 10.15744/2348-9820.4.203

Received Date: October 18, 2015 Accepted Date: April 15, 2016 Published Date: April 18, 2016

\begin{abstract}
Cleft lip is a common craniofacial anomaly. Median cleft lip is a midline vertical cleft through the upper lip. Of all the types of clefts, minimal Median cleft of the upper lip is a very rare craniofacial anomaly. This defect is thought to be associated with hypertelorism or hypotelorism. Although a number of plastic surgical procedures have been described in the literature, we describe in this case report a simple frenectomy as a treatment modality for minimal median cleft of the upper lip with good esthetic results.
\end{abstract}

Keywords: Minimal; Median cleft; Upper lip

\section{Introduction}

Median cleft lip is defined as any congenital vertical cleft through the centre of the upper lip. Median cleft lip is one of the rare craniofacial anomalies [1]. The incidence is about 1:10,000,000 births [2]. This may occur as a sporadic event or as a part of an inherited sequence of anomalies. It arises embryologically from incomplete merging of the median nasal prominences. Midline cleft lip defects occur when medial nasal prominence derivatives are deviant or absent [3].

Superior labial frenum is a membranous fold of mucous membrane which provides stability and support for upper lip. It is called as maxillary frenum or frenulum labii superioris. It extends from the inferior surface of upper lip to the middle portion of the labial surface of the alveolar process between the central incisors. It is attached to the external layer of the periosteum, connective tissue of the maxillary suture and the alveolar process [4-8]. Many studies have reviewed the different frenum morphologies in both primary and permanent dentition [9-13].

An abnormal frenal attachment is an etiology for midline diastema and can be an indicator of a syndrome when associated with other features [9-11,14]. An abnormal frenal attachment can lead to frenal pull which may result in extension of gingival sulcus which in turn encourages plaque accumulation and increases the severity of periodontal pockets [15]. It can cause recession of gums and can also interfere with effective tooth brushing leading to inability to remove plaque [16,17]. It may also prejudice the denture fit on retention. A torn labial fenum can be an indicator of child abuse [18].

Here we present a case report of a frenectomy as a treatment modality for minimal median cleft of upper lip with esthetic results.

\section{Case Report}

A 9 year old female patient reported to the Department of Pediatric Dentistry, with a chief complaint of spacing in the upper front tooth region and interference in brushing. The patient's medical history was insignificant. No consanguinity in marriage was noted. Extra oral examination revealed a minimal median cleft of the upper lip (Figure 1). She had a normal nose; a normal intercanthal distance and no other craniofacial abnormalities. Intra-oral examination revealed that primary and secondary palates were intact. The movements of soft palate were normal. A high frenal attachment and midline spacing between maxillary central incisors $(4.5 \mathrm{~mm}$ ) was also recorded (Figure 2). There was no median bony defect found intraorally or on the intraoral periapical radiograph (Figure 3). 


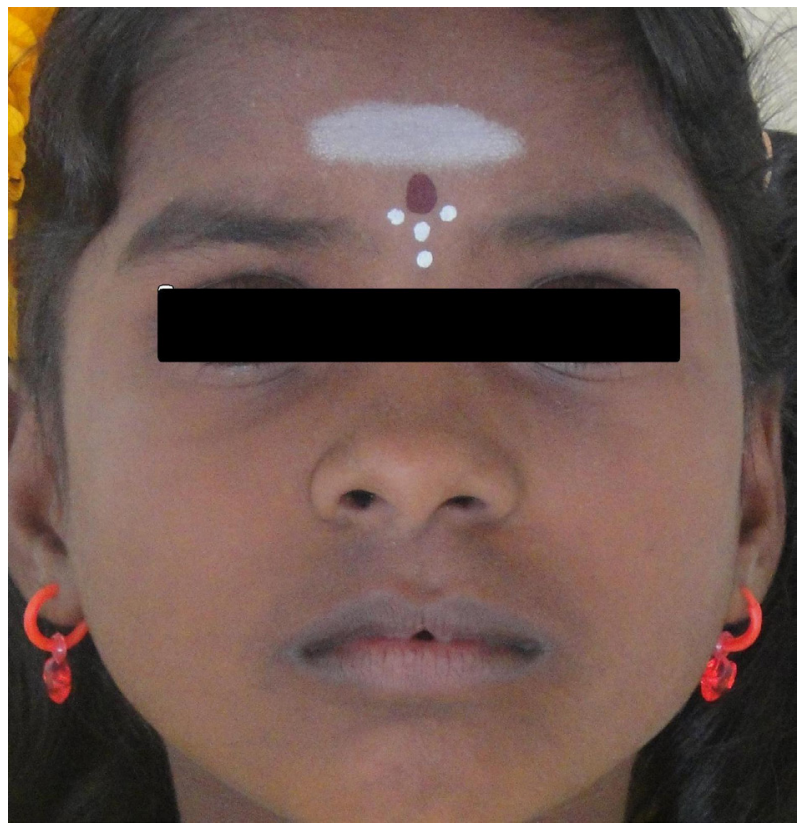

Figure 1: Minimal median cleft of the upper lip

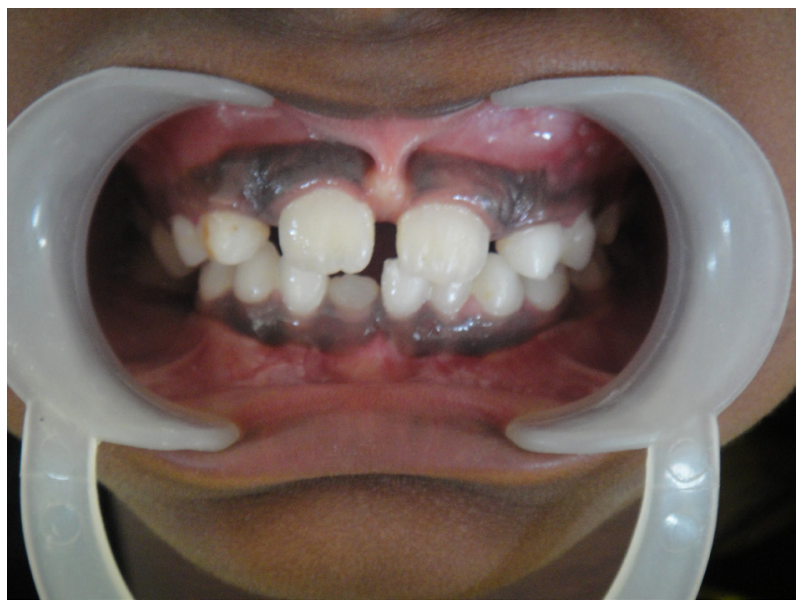

Figure 2: Midline spacing between central incisors

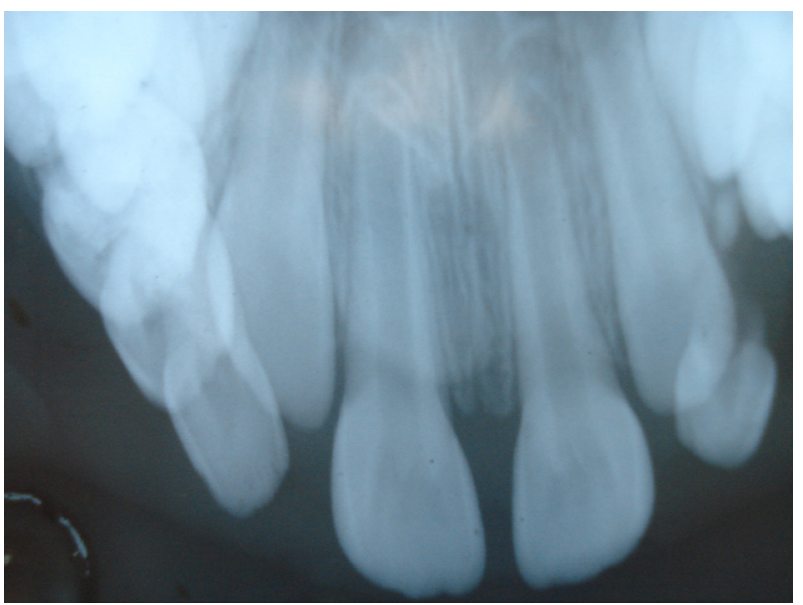

Figure 3: Intraoral periapical radiograph showing no bony defects

A simple diagnostic test, i.e. blanching test was performed for an abnormal high frenum by observing the location of the alveolar attachment when intermittent pressure was exerted on the frenum. It was observed at the end of the test that the patient had a high frenal attachment. If a heavy band of tissue with a broad fanlike base is attached to the palatine papillae and produces blanching of the papilla, it is safe to predict that the frenum will unfavorably influence the development of the anterior occlusion. A diagnosis of tectolabial frenum was made based on modified Sewerin Typology [12,19]. 
The treatment decided for this patient was surgical removal of the tectolabial frenum. Basic blood investigations were done and the reports were well within normal limits. Informed consent was obtained from parents for the surgical removal of tectolabial frenum.

Frenectomy was carried out under local anesthesia with incision using No.11 Bard Parker blade. In this technique, lateral incisions were made on either side of the frenum to the depth of the underlying bone. The free marginal tissues on the mesial side of the central incisions were not disturbed.

The wedge of tissue was picked up with tissue forceps and excised with tissue shears at the area close enough to the origin of the frenum to provide a desirable cosmetic effect. Sutures were placed to identify the free tissue margins on either side of the removed tissue and a periodontal pack was placed for a week. The patient was advised to return after a week for suture removal and periodical follow-up once a month. Follow up after 1 month showed good healing of the soft tissues (Figure 4) and after a period of 6 months showed remarkable improvement in aesthetics with the closure of minimal median cleft of the upper lip (Figure 5).

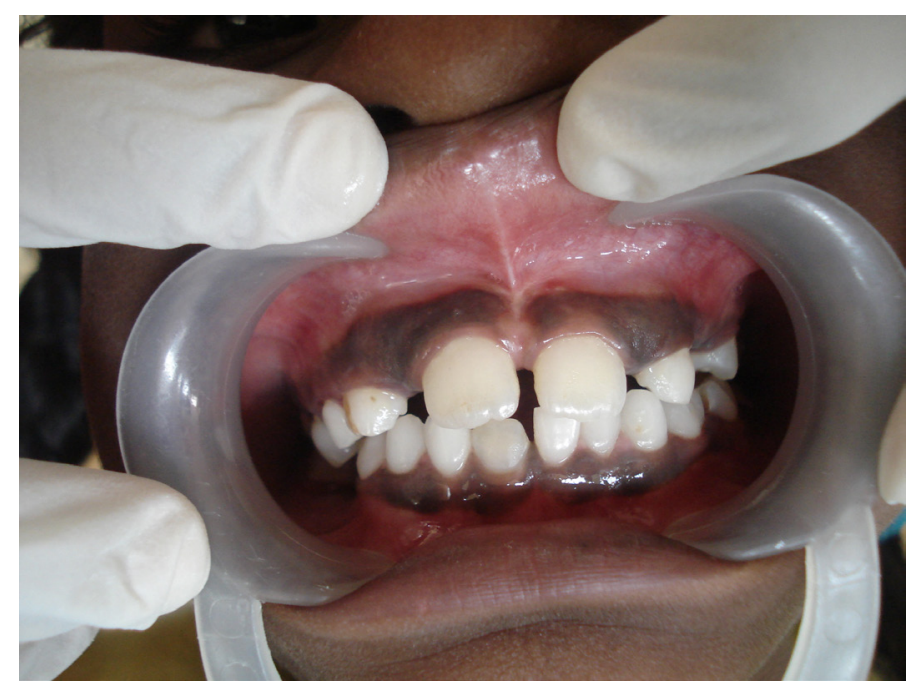

Figure 4: One month follow up

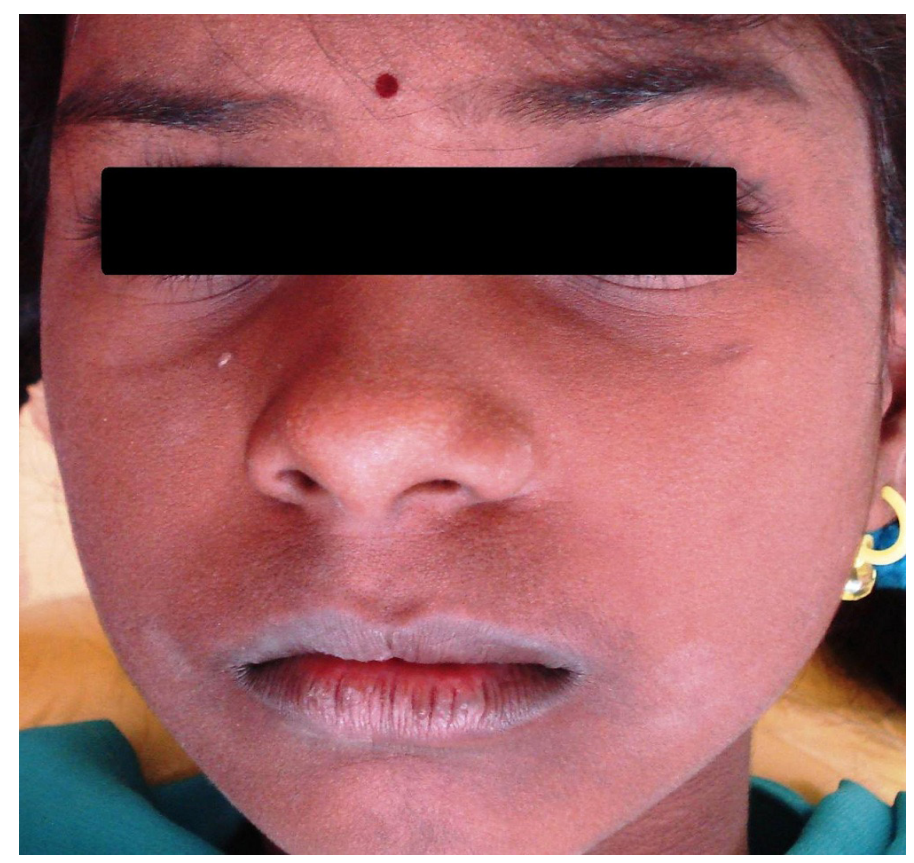

Figure 5: Improved esthetics after correction

\section{Discussion}

Median cleft lip is a rare condition among the craniofacial anomalies. Three separate groups of facial anomaly syndromes associated with the complete median cleft lip have been described [20]. Those maybe associated with orbital hypotelorism, hypertelorism and normotelorism. Our patient was typical case of minimal median cleft lip and normotelorism. 
The developmental error that results in midline facial defects usually occurs in third week of gestation. At this time bilateral thickening of frontonasal process occurs. These thickenings of the surface ectoderm become the medial and lateral nasal prominences that contribute to the formation of nasal philtrum and lateral lip. Fusion of the globular processes is responsible for formation of the anterior portion of the hard palate, the central dentoalveolar ridge, central upper lip and philtrum. It is essential that fusion of these prominences occur for normal development of upper lip. Any disturbance during this time can result in abnormalities of the upper lip.

The labial frenum is an anatomical structure formed by mucous membrane and connective tissue. Frenum is a dynamic and changeable structure and is subject to change in shape, size and position during the different stages of growth and development. It was thought that an abnormal high labial frenal attachment interfered with the closure of midline diastema. Springer suggested that a diastema and an abnormal frenulum without other signs of midline cleft might represent a minimal form of median cleft or failure of facial medialization [21].

Various surgical techniques have been recommended for the correction of medial cleft of the lip [22]. However in our case we found that surgical removal of the tectolabial frenum resulted in satisfactory correction of the minimal median cleft of the lip. This might be due to the release of the fibres of the abnormal frenum, in this case the tectolabial frenum which might have been attached to the inferior border of the upper lip. So as suggested earlier we would like to propose that, other than the surgical techniques that have resulted in excellent results in correcting the upper lip, the clinician should also check for an abnormal frenal attachment and surgical removal of the frenal attachment could have a beneficial effect on the appearance of the lip.

Diastema is a space/gap seen between two teeth. Midline diastema could be transient or can be created by developmental, pathological or iatrogenic factors. In this case, a high frenal attachment was the major etiological factor causing midline spacing. This was confirmed by positive indication of blanching test. Treatment of diastema varies and it requires correct diagnosis of its etiology and early intervention to its specific etiology. Correct diagnoses include medical and dental history, radiographical and clinical examination and possibly tooth size evaluation. No treatment is initiated if diastema is transient, so the space can close after the eruption of maxillary canines.

Many treatment methods have been suggested for midline diastema like porcelain veneers, orthodontic treatment with use of magnets and treatment of the etiological factor. Pathological causes like supernumerary teeth, midline cyst can be removed surgically and orthodontic closure of the space can be done by fixed orthodontic appliances [23]. When a pathological cause is identified between central incisors, the mesial movement during canine eruption is also impeded.

Thus in our case an attempt was made to remove the etiology, even though the patient was 9 years old considering the fact that there will be maximum active mesial movement of the canine during eruption. The patient was followed up after six months whereby closure of space of about $3.5 \mathrm{~mm}$ was noted. The remaining $1 \mathrm{~mm}$ diastema is expected to close when the canines start to erupt at around 12-13yrs of age. Hence in the present case we found that surgical removal of the tectolabial frenum not only corrected the minimal median cleft of the upper lip to a certain extent but also the midline diastema reduced to a great extent. This has been supported by other studies which found that there was a spontaneous closure of midline diastema following frenectomy [24].

\section{Conclusion}

An accurate diagnosis is therefore necessary before treatment can be initiated. Timely intervention can result in excellent positive results even in the mixed dentition stage as seen in the above case.

\section{References}

1. Springer IN, Sprengel M, Terheyden H, Suhr MA, Härle F, et al. (2004) Wedge excision: treatment of choice in minimal median clefts of the upper lip. Plast Reconstr Surg 114: 812-4.

2. Demyer W (1967) The median cleft face syndrome. Neurology 17: 961-71.

3. Johnston MC, Sulik KK (1979) Some abnormal patterns of development in the craniofacial region. Birth Defects Orig Artic Ser 15: 23-42.

4. Parker DB (1937) Surgical consideration of abnormal frena. Int J Orthod Oral Surg 23: 1141-8.

5. Jacobs MH (1932) The abnormal frenum labii. Dent Cosmos 74: 436-9.

6. Curran M (1950) Superior labial frenotomy. J Am Dent Assoc 41: 419-22.

7. Dadeghi EM, Van Swol RL, Eslami A (1984) Histological analysis of the hyperplastic maxillary anterior frenum. J Oral Maxillofac Surg 42: 765-70.

8. Ceremello PJ (1953) The superior labial frenum and the midline diastema and their relation to growth and development of the oral structures. Am J Orthod 39: $120-39$.

9. DeMyer W (1975) Median facial malformations and their implications for brain malformations. Birth Defects Orig Artic Ser 11: 155-81.

10. Khandekar BV, Srinivasan S, Mokal NJ (2010) Median cleft lip: A new method of surgical repair. Indian J Plast Surg 43: 111-3.

11. Bishara SE (1985) Dentofacial findings in a child with unrepaired median cleft of the lip at 4 years of age. Am J Orthod 88: 157-62.

12. Díaz-Pizán ME, Lagravère MO, Villena R (2006) Midline diastema and frenum morphology in primary dentition. J Dent Child 73: 11-4.

13. Patel NP, Tantri MD (2010) Median cleft of the upper lip: a rare case. Cleft Palate Craniofac J 47: 642-4. 
14. Popovich F, Thompson GW, Main PA (1977) The maxillary interincisal diastema and its relationship to the superior labial frenum and intermaxilary suture. Angle Orthod 47: 265-71.

15. Kaimenyi JT (1998) Occurrence of midline diastema and frenum attachments amongst school children in Nairobi, Kenya. Indian J Dent Res 9: 67-71.

16. Pushpavathi N, Nayak RP (1997) The effect of mouth breathing upper lip coverage, lip seal and frenal attachment on the gingivae of 11-14 year old Indian school children. J Indian Soc Pedod Prev Dent 15: 100-3.

17. Addy M, Dummer PM, Hunter ML, Kingdon A, Shaw WC (1987) Study of the association of frenal attachment, lip coverage and vestibular depth with plaque and gingivitis. J Periodontol 58: 752-7.

18. Macintyre DR, Jones GM, Pinckney RC (1986) The role of dental practitioner in the management of non-accidental injury to children. Br Dent J 161: 108-10.

19. Sewerin I(1971) Prevalence of variations and anomalies of the upper labial frenum. Acta Odontol Scand 29: 487-96.

20. Kumar S, Gandotra D (2013) An aesthetic and rapid approach to treat midline diastema. J Cranio Max Dis 2: 175-8.

21. Munshi A, Munshi AK (2001) Midline space closure in the mixed dentition: A case report. J Indian Soc Pedod Prev Dent 19: 57-60.

22. Huang WG, Creath CJ (1995) The midline diastema: A review of its etiology and treatment. Pediatr Dent 17: 171-9.

23. Follin ME (1985) Orthodontic movement of maxillary incisor into the midline: A case report. Swed Dent J 9: 9-13.

24. Koora K, Muthu MS, Rathna PV (2007) Spontaneous closure of midline diastema following frenectomy. J Indian Soc Pedod Prev Dent 25: $23-6$.

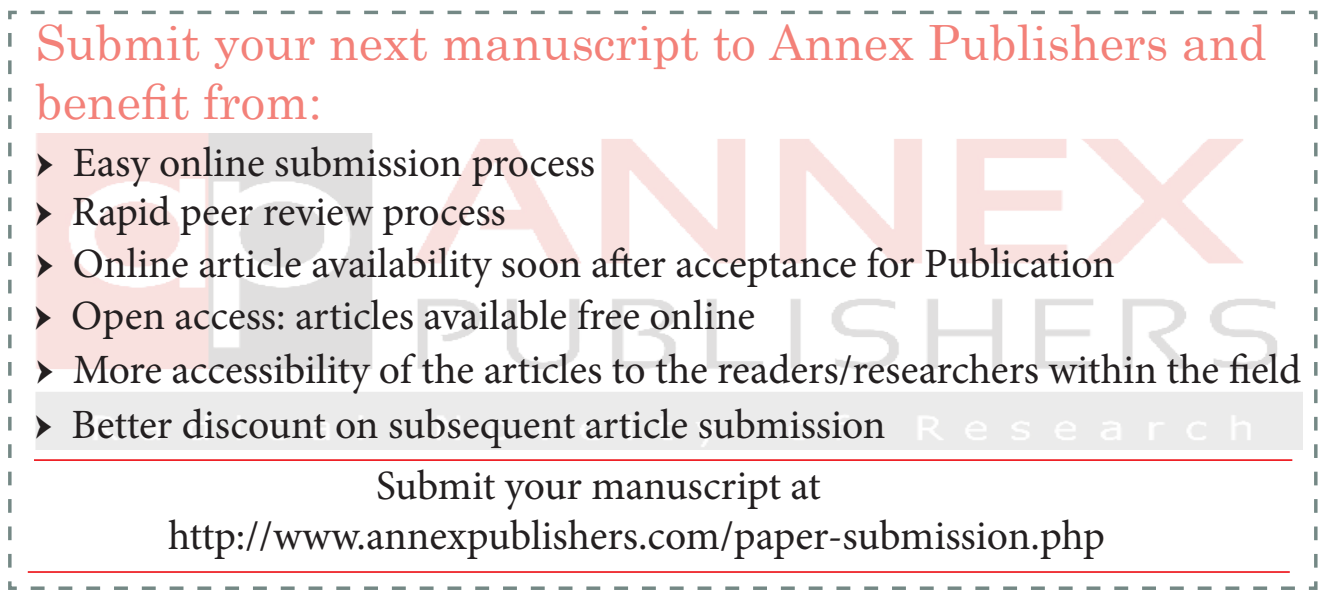

